\section{A clinical prediction tool to predict urinary tract infection in pediatric febrile patients younger than 2 years old: a retrospective analysis of a fever registry}

\author{
Yun Seong Park', Jin Hee Lee ${ }^{1,2}$, Young Ho Kwak' ${ }^{2}$, Jae Yun Jung ${ }^{2}$, \\ Hyuksool Kwon', Yoo Jin Choi ${ }^{3}$, Dong Bum Suh', Bongjin Lee², \\ Min-Jung Kim ${ }^{4}$, Do Kyun Kim²
}

1Department of Emergency Medicine, Seoul National University Bundang Hospital, Seongnam, Korea
${ }^{2}$ Department of Emergency Medicine, Seoul National University College of Medicine, Seoul, Korea
${ }^{3}$ Department of Emergency Medicine, Ajou University School of Medicine, Suwon, Korea
${ }^{4}$ Department of Emergency Medicine, CHA Bundang Medical Center, CHA University, Seongnam, Korea

Objective Urinary tract infection (UTI) is a significant issue in young febrile patients due to potential long-term complications. Early detection of UTI is crucial in pediatric emergency departments (PEDs). We developed a tool to predict UTIs in children.

Methods Clinical data of patients $<24$ months of age with a fever and UTI or viral infection were extracted from the fever registry collected in two PEDs. Stepwise multivariate logistic regression was performed to establish predictors of identified eligible clinical variables for the derivation of the prediction model.

Results A total of 1,351 patients were included in the analysis, 643 patients from A hospital (derivation set) and 708 patients from $B$ hospital (validation set). In the derivation set, there were more girls and a lower incidence of a past history of UTI, older age, less fever without source, and more family members with upper respiratory symptoms in the viral infection group. The stepwise regression analysis identified sex (uncircumcised male), age ( $\leq 12$ months), a past history of UTI, and family members with upper respiratory symptoms as significant variables.

Conclusion Young febrile patients in the PED were more likely to have UTIs if they were uncircumcised boys, were younger than 12 months of age, had a past history of UTIs, or did not have families with respiratory infections. This clinical prediction model may help determine whether to perform urinalysis in the PED.

Keywords Infant; Urinary tract infections; Emergency service, hospital; Clinical decision rules
elSSN: 2383-4625

Received: 12 October 2020

Revised: 28 November 2020

Accepted: 16 December 2020

Correspondence to: Jin Hee Lee Department of Emergency Medicine, Seoul National University Bundang Hospital, Seoul National University College of Medicine, 82 Gumi-ro

173beon-gil, Bundang-gu, Seongnam 13620, Korea

E-mail: gienee@snubh.org

ORCID

https://orcid.org/0000-0002-2385-2834

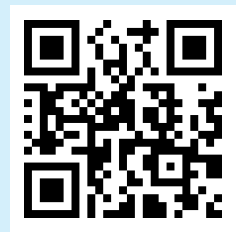

How to cite this article:

Park YS, Lee JH, Kwak YH, Jung JY, Kwon H, Choi YJ, Suh DB, Lee B, Kim MJ, Kim DK. A clinical prediction tool to predict urinary tract infection in pediatric febrile patients younger than 2 years old: a retrospective analysis of a fever registry. Clin Exp Emerg Med 2021;8(4):314-324. https://doi.

org/10.15441/ceem.20.134

This is an Open Access article distributed under the terms of the Creative Commons Attribution Non-Commercial License (https:// creativecommons.org/licenses/by-nc/4.0/). 


Wapsule $\begin{aligned} & \text { What is already known } \\ & \text { The American Academy of Pediatrics suggested the following criteria for performing a urinalysis in girls and boys. For } \\ & \text { girls: white race, age }<12 \text { months, temperature } \geq 39^{\circ} \mathrm{C} \text {, fever } \geq 48 \text { hours, and no other fever source; for boys: uncircum- } \\ & \text { cised, nonblack race, temperature } \geq 39^{\circ} \mathrm{C} \text {, fever } \geq 24 \text { hours, and no other fever source. } \\ & \text { What is new in the current study } \\ & \text { Temperature } \geq 39^{\circ} \mathrm{C} \text {, fever } \geq 48 \text { hours or fever } \geq 24 \text { hours did not help predict urinary tract infection. They were more } \\ & \text { likely to have urinary tract infections if they were uncircumcised boys, younger than } 12 \text { months, had a past history of } \\ & \text { urinary tract infections, or didn't have families with respiratory infections. }\end{aligned}$

\section{INTRODUCTION}

Urinary tract infections (UTIs) are one of the most common causes of serious bacterial infections in young pediatric patients. ${ }^{1}$ The prevalence of UTIs reaches 7\% among children younger than 2 years old who visit the emergency department (ED) with a fever. ${ }^{2}$ UTIs in children are found to have potential long-term complications, such as renal scarring, impaired renal growth, hypertension, and end-stage renal disease. ${ }^{3}$

A urine sample for confirmative diagnosis and urine culture should be obtained through urinary catheterization or suprapubic aspiration, although because both are invasive, most guidelines suggest that the screening urine test be performed using a clean catch method in a urine bag. ${ }^{4.5} \mathrm{~A}$ two-step process has emerged, although it is challenging because it is time-consuming and difficult to perform. ${ }^{6}$

Because many studies are retrospective case-control or cohort studies, some biases may be involved. ${ }^{2,7-9}$ The American Academy of Pediatrics (AAP) guideline suggests risk factors of UTIs in children. The risk factors are white race, age $<12$ months, temperature $>39^{\circ} \mathrm{C}$, duration of fever $>2$ days, and absence of another source of infection for girls and nonblack race, temperature $>39^{\circ} \mathrm{C}$, duration of fever $>24$ hours, and absence of another source of infection for boys.

We have a registry of febrile pediatric patients $<5$ years of age that was prospectively collected using structured medical records. Using these data, a study was designed to develop a clinical prediction tool to distinguish patients $<2$ years of age with possible UTIs from those with viral infections (VIs). We hypothesized that age, the severity of fever, uncircumcised boys, duration of fever, and other demographic factors could be factors that predict the probability of UTIs in young children.

\section{METHODS}

\section{Study design and settings}

From August 2016 to February 2018, a registry was prospectively collected using predefined structured medical records of febrile pediatric patients aged $<5$ years (Appendix 1) admitted to the pediatric EDs of two teaching hospitals, which are tertiary care medical centers. During the study period, the medical records were regularly reviewed by attending pediatric emergency physicians for quality and reliability. We retrospectively analyzed the records of patients aged $<2$ years with UTIs or VIs using this registry.

Each hospital included 20,000 pediatric patients annually in the census. The pediatric patients were evaluated by emergency physicians who were supervised by attending pediatricians using a two-step process for a diagnosis of UTI. First, a urine bag was attached to the perineum of the infant to collect the urine specimen, and urinary catheterization was performed when a positive random urine test was obtained. ${ }^{6}$ The institutional review board of each hospital approved the study (Seoul National University Bundang Hospital IRB No. B-1811-507-103). As a retrospective study, informed consent was waived.

\section{Participants}

We extracted data from patients $<2$ years of age with UTIs and VIs from this registry. Data of the patients who met the defined criteria were extracted by one physician and examined by another attending pediatric emergency physician.

UTIs were defined as the presence of at least 50,000 colonyforming units per milliliter of a uropathogen cultured from a urine specimen through catheterization based on the AAP criteria. ${ }^{4}$ Vls were defined as cases in which a bacterial infection was not detected through medical records or laboratory or radiological test results in patients who were discharged from the ED or hospital 
with a diagnosis of VI. We defined VI based on the data obtained from the ED.

We excluded patients whose urine samples were not collected, patients with bacteremia who did not have a UTI, patients with hemato-oncologic malignancies, patients with central nervous system infection, patients without essential data, immunocompromised patients, patients with a bacterial infection other than a UTI, patients with Kawasaki disease, patients with congenital anomalies, patients who did not meet the UTI criteria, and patients who were lost to follow-up.

\section{Procedures}

Clinical informations of the patients included in the fever registry were sex, age (months), past medical history, highest body temperature (BT) in degree Celsius (through history taking or measurement in the ED), duration of fever, activity (normal, mildly decreased, decreased, and poor), amount of feeding (100\%, 80\% to $<100 \%, 50 \%$ to $<80 \%$, and $<50 \%$ ), decrease in urine volume (normal, mildly decreased, and decreased) as reported by the guardian, vaccination within 2 days, attendance at a daycare center, presence of siblings or family members with upper respiratory symptoms within 1 week, presence of rashes, and capillary refill time (CRT) or presence of fever without source (FWS).

The patients were divided into two age groups as follows: $<12$ months and 12-24 months of age. The patients were divided into the following categories depending on the duration of fever: $<24$, 24 to $<48,48$ to $<72,72$ to $<96$, and $\geq 96$ hours. The patients were also divided into the following categories depending on their BT: $<38^{\circ} \mathrm{C}, 38 \leq \mathrm{BT}<39^{\circ} \mathrm{C}, 39 \leq \mathrm{BT}<40^{\circ} \mathrm{C}$, and $\geq 40^{\circ} \mathrm{C}$.

We planned to derive and validate this prediction model in the present study. The prediction model was derived from the A hospital dataset and validated with the B hospital dataset. Because

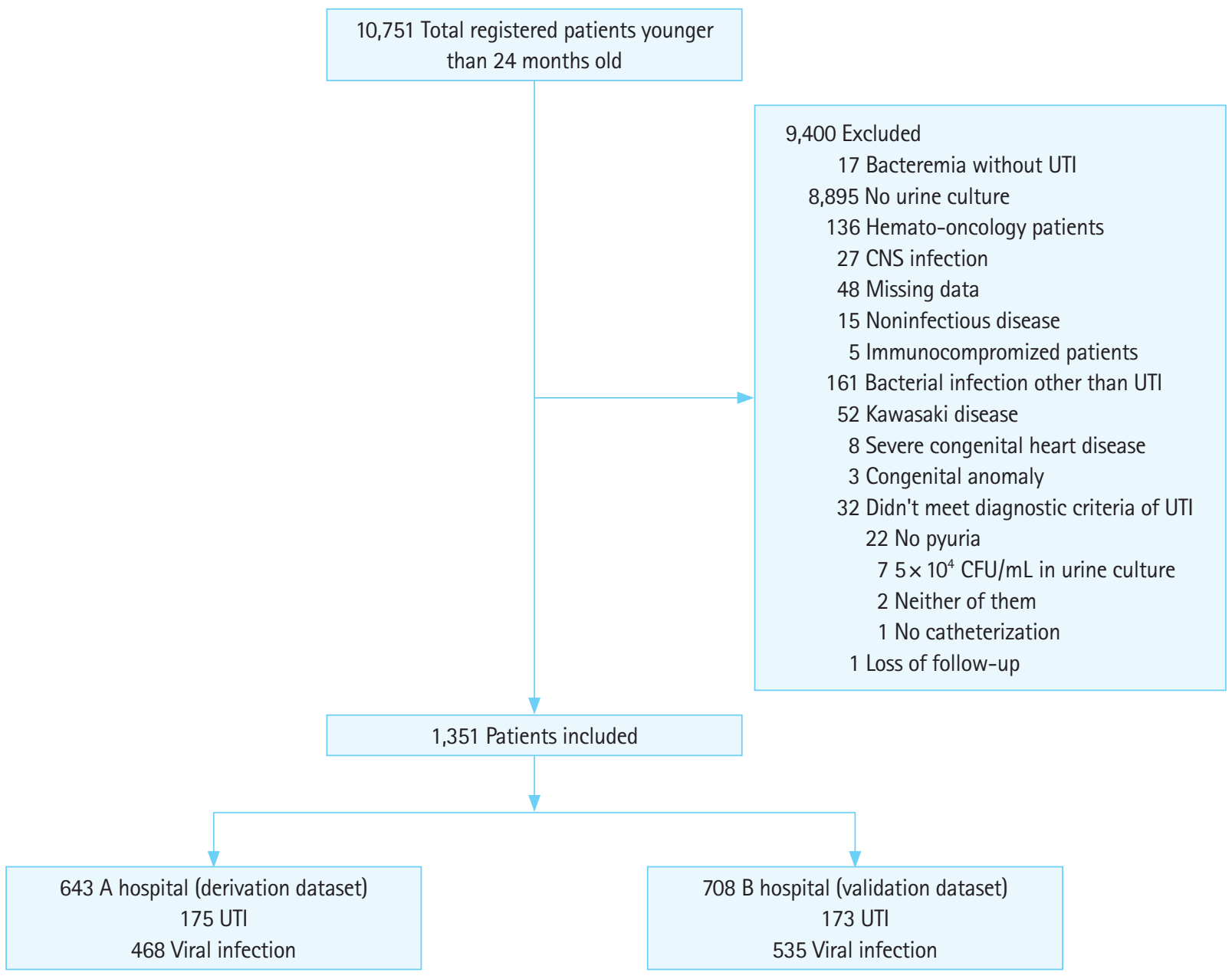

Fig. 1. Study flow diagram of the pediatric patients included. A total of 10,751 pediatric patients were considered for study inclusion, and 1,351 patients were included in this study after applying the exclusion criteria. There were 643 patients from A hospital (derivation dataset) and 708 patients from B hospital (validation dataset). In A hospital, there were 175 urinary tract infections (UTIs) and 468 viral infections and in B hospital, there were 173 UTIs and 535 viral infections. CNS, central nervous system; CFU, colony forming units. 
the two hospitals differed in severity and patient distribution, it was determined that generalization would be possible.

If urine cultures were collected before discharge, the attending pediatric emergency physicians and assigned research nurses checked all the culture results.

\section{Outcomes}

The primary outcome was to develop a predictive tool that could predict whether febrile young children had UTI.

\section{Statistics}

All data were analyzed using Stata ver. 14.2 (Stata Corp., College Station, TX, USA). We performed Student t-tests for continuous variables and chi-square tests for categorical variables to evaluate the differences in the clinical variables between the UTI and VI groups.

Univariate and multivariate logistic regression analyses were performed to identify eligible clinical variables that could be used to estimate the risk of UTI. We performed stepwise multivariate logistic regression analysis and obtained $\mathrm{P}$-values and limits $(<0.2)$ to establish predictors of identified eligible clinical variables. To validate the competency of the model, we used the validation dataset (B hospital) and compared the derivation model with the AAP model (AAP guidelines mention clinical risk factors, and these factors are referred to as the "AAP model" in this study). The diagnostic accuracy of the model was evaluated based on sensitivity, specificity, and area under the receiver operating characteristic curve (AUROC). Missing values were not replaced by other values, and cases with missing values were excluded. We then performed a tree analysis using the party package with the identified variables. ${ }^{10}$

Data are described as the means \pm standard deviations for continuous variables and numbers (percentages) for categorical variables. The results of the logistic regression analysis revealed odds ratios with 95\% confidence intervals.

\section{RESULTS}

The total number of patients enrolled in the fever registry of the two hospitals was 10,751, and the prevalence of UTls among patients with fever, who were $<2$ years of age, was approximately $3.2 \%(348 / 10,751)$. After excluding 9,400 individuals, 1,351 patients were included in the analysis (Fig. 1). A total of 643 patients were included in the derivation dataset (A hospital), and 708 patients were included in the validation dataset (B hospital). The overall proportion of UTIs was 25.8\% (348/1,351). There were 175 UTIs and 468 VIs in the B hospital dataset and 173 UTIs and 535 Vls in the A hospital dataset (Fig. 1). There was no difference in
Table 1. Derivation dataset (A hospital) versus validation dataset (B hospital) and demographics

\begin{tabular}{|c|c|c|c|c|}
\hline Characteristics & $\begin{array}{c}\text { Total } \\
(n=1,351)\end{array}$ & $\begin{array}{c}\text { Derivation } \\
\text { dataset } \\
\text { (A hospital) } \\
(n=643)\end{array}$ & $\begin{array}{c}\text { Validation } \\
\text { dataset } \\
\text { (B hospital) } \\
(n=708)\end{array}$ & P-value \\
\hline Urinary tract infection & 348 & 175 (27.22) & $173(24.44)$ & 0.243 \\
\hline Sex, male & 683 & 351 (54.59) & 332 (46.89) & 0.005 \\
\hline Disposition & & & & $<0.001$ \\
\hline Discharge & 818 & $336(52.26)$ & $482(68.08)$ & \\
\hline Ward admission & 528 & 303 (47.12) & 225 (31.78) & \\
\hline ICU admission & 3 & $3(0.47)$ & $0(0)$ & \\
\hline Transfer & 2 & $1(0.16)$ & $1(0.14)$ & \\
\hline Past history & & & & 0.327 \\
\hline None & 1,104 & $518(80.56)$ & $586(82.77)$ & \\
\hline Other & 140 & $75(11.66)$ & 65 (9.18) & \\
\hline Genito urinary & 107 & 50 (7.78) & 57 (8.05) & \\
\hline Age (mo) & & & & $<0.001$ \\
\hline $0-11$ & 925 & 475 (73.87) & 450 (63.56) & \\
\hline $12-24$ & 426 & $168(26.13)$ & $258(36.44)$ & \\
\hline Body temperature $\left({ }^{\circ} \mathrm{C}\right)$ & & & & $<0.001$ \\
\hline$<38$ & 417 & 169 (26.28) & $248(35.03)$ & \\
\hline 38 to $<39$ & 641 & 369 (57.39) & $272(38.42)$ & \\
\hline 39 to $<40$ & 251 & $94(14.62)$ & 157 (22.18) & \\
\hline$\geq 40$ & 42 & $11(1.71)$ & $31(4.38)$ & \\
\hline Fever without source & & & & 0.065 \\
\hline No & 731 & $129(79.14)$ & 602 (85.03) & \\
\hline Yes & 140 & $34(20.86)$ & $106(14.97)$ & \\
\hline NA & 480 & & & \\
\hline Duration of fever (hr) & & & & $<0.001$ \\
\hline$<24$ & 535 & $303(47.57)$ & $232(32.77)$ & \\
\hline 24 to $<48$ & 375 & $158(24.80)$ & 217 (30.65) & \\
\hline 48 to $<72$ & 183 & 63 (9.89) & 120 (16.95) & \\
\hline 72 to $<96$ & 100 & 40 (6.28) & 60 (8.47) & \\
\hline$\geq 96$ & 152 & $73(11.46)$ & 79 (11.16) & \\
\hline NA & 6 & & & \\
\hline Activity & & & & 0.015 \\
\hline Normal & 807 & 392 (65.44) & 415 (61.85) & \\
\hline Mildly decreased & 277 & 109 (18.20) & 168 (25.04) & \\
\hline Decreased & 145 & 74 (12.35) & 71 (10.58) & \\
\hline Poor & 34 & $17(2.53)$ & $17(2.53)$ & \\
\hline NA & 88 & & & \\
\hline Feeding (\%) & & & & 0.032 \\
\hline 100 & 714 & 360 (58.63) & 354 (50.86) & \\
\hline 80 to $<100$ & 224 & $90(14.66)$ & 134 (19.25) & \\
\hline 50 to $<80$ & 198 & 88 (14.33) & $110(15.80)$ & \\
\hline$<50$ & 174 & 76 (12.38) & 98 (14.08) & \\
\hline NA & 41 & & & \\
\hline Urination & & & & $<0.001$ \\
\hline Normal & 1,029 & 475 (84.22) & $554(79.60)$ & \\
\hline Mildly decreased & 67 & $50(8.87)$ & $17(2.44)$ & \\
\hline Decreased & 164 & 39 (6.91) & 125 (17.96) & \\
\hline NA & 91 & & & \\
\hline
\end{tabular}

(continued to the next page) 
Table 1. Continued

\begin{tabular}{|c|c|c|c|c|}
\hline Characteristics & $\begin{array}{c}\text { Total } \\
(n=1,351)\end{array}$ & $\begin{array}{c}\text { Derivation } \\
\text { dataset } \\
\text { (A hospital) } \\
(n=643)\end{array}$ & $\begin{array}{l}\text { Validation } \\
\text { dataset } \\
\text { (B hospital) } \\
(n=708)\end{array}$ & P-value \\
\hline Vaccination within 2 day & & & & 0.935 \\
\hline No & 964 & 487 (93.65) & 477 (93.53) & \\
\hline Yes & 66 & $33(6.35)$ & $33(6.47)$ & \\
\hline NA & 321 & & & \\
\hline Daycare center & & & & $<0.001$ \\
\hline No & 753 & $330(90.41)$ & $423(77.61)$ & \\
\hline Yes & 157 & $35(9.59)$ & $122(22.39)$ & \\
\hline NA & 441 & & & \\
\hline Sibling & & & & 0.002 \\
\hline No & 686 & $323(71.15)$ & $363(62.05)$ & \\
\hline Yes & 353 & $131(28.85)$ & $222(37.95)$ & \\
\hline NA & 312 & & & \\
\hline \multicolumn{4}{|c|}{ Family members with upper respiratory symptoms } & 0.002 \\
\hline No & 657 & $302(66.08)$ & $355(75.21)$ & \\
\hline Yes & 272 & 155 (33.92) & $117(24.79)$ & \\
\hline NA & 422 & & & \\
\hline Rash & & & & 0.391 \\
\hline No & 1,218 & $591(94.86)$ & $627(95.87)$ & \\
\hline Yes & 59 & $32(5.14)$ & $27(4.13)$ & \\
\hline NA & 74 & & & \\
\hline Capillary refill time (sec) & & & & 0.013 \\
\hline$<2$ & 691 & 192 (99.48) & 499 (95.78) & \\
\hline$\geq 2$ & 23 & $1(0.52)$ & $22(4.22)$ & \\
\hline NA & 637 & & & \\
\hline
\end{tabular}

Values are presented as number (\%).

ICU, intensive care unit; NA, not applicable.

Table 2. Viral infection versus urinary tract infection demographic characteristics of the derivation dataset

\begin{tabular}{|c|c|c|c|}
\hline & $\begin{array}{l}\text { Viral infection } \\
\quad(n=468)\end{array}$ & $\begin{array}{l}\text { Urinary tract } \\
\text { infection } \\
(n=175)\end{array}$ & P-value \\
\hline Duration of fever (hr) & $33.00 \pm 42.97$ & $33.10 \pm 36.44$ & 0.327 \\
\hline Body temperature $\left({ }^{\circ} \mathrm{C}\right)$ & $38.42 \pm 0.72$ & $38.24 \pm 0.89$ & 0.070 \\
\hline Sex & & & $<0.001$ \\
\hline Female & $245(52.35)$ & $47(26.86)$ & \\
\hline Male (all were uncircumcised) & $223(47.65)$ & $128(73.14)$ & \\
\hline Past history & & & 0.008 \\
\hline None & 386 (82.48) & $132(75.43)$ & \\
\hline Other & $55(11.75)$ & $20(11.43)$ & \\
\hline Genito-urinary & $27(5.77)$ & $23(13.14)$ & \\
\hline Age (mo) & & & $<0.001$ \\
\hline$<12$ & $316(67.52)$ & $159(90.86)$ & \\
\hline$\geq 12$ & $152(32.48)$ & $16(9.14)$ & \\
\hline Body temperature $\left({ }^{\circ} \mathrm{C}\right)$ & & & 0.070 \\
\hline$<38$ & $113(24.15)$ & $56(32.00)$ & \\
\hline 38 to $<39$ & $275(58.76)$ & $94(53.71)$ & \\
\hline 39 to $<40$ & $74(15.81)$ & $20(11.43)$ & \\
\hline$\geq 40$ & $6(1.28)$ & $5(2.86)$ & \\
\hline
\end{tabular}

(continued to the next)
Table 2. Continued

\begin{tabular}{|c|c|c|c|}
\hline & $\begin{array}{l}\text { Viral infection } \\
\quad(n=468)\end{array}$ & $\begin{array}{l}\text { Urinary tract } \\
\text { infection } \\
(n=175)\end{array}$ & P-value \\
\hline Fever without source & & & 0.004 \\
\hline No & $103(84.43)$ & $26(63.41)$ & \\
\hline Yes & 19 (15.57) & 15 (36.59) & \\
\hline NA & 346 & 134 & \\
\hline Duration of fever (hr) & & & 0.327 \\
\hline$<24$ & $223(48.06)$ & $80(46.24)$ & \\
\hline 24 to $<48$ & $115(24.78)$ & $43(24.86)$ & \\
\hline 48 to $<72$ & 51 (10.99) & $12(6.94)$ & \\
\hline 72 to $<96$ & $26(5.60)$ & $14(8.09)$ & \\
\hline$\geq 96$ & 49 (10.56) & $24(13.87)$ & \\
\hline NA & 4 & 2 & \\
\hline Activity & & & 0.526 \\
\hline Well & $291(66.14)$ & $101(63.52)$ & \\
\hline Mildly decreased & $76(17.27)$ & $33(20.75)$ & \\
\hline Decreased & 53 (12.05) & $21(13.21)$ & \\
\hline Poor & $20(4.55)$ & $4(2.52)$ & \\
\hline NA & 28 & 16 & \\
\hline Feeding (\%) & & & 0.005 \\
\hline 100 & 265 (59.28) & 95 (56.89) & \\
\hline 80 to $<100$ & 71 (15.88) & 19 (11.38) & \\
\hline 50 to $<80$ & $68(15.21)$ & $20(11.98)$ & \\
\hline$<50$ & $43(9.62)$ & $33(19.76)$ & \\
\hline NA & 21 & 8 & \\
\hline Urination & & & 0.485 \\
\hline Well & 349 (84.30) & $126(84.00)$ & \\
\hline Mildly decreased & $39(9.42)$ & $11(7.33)$ & \\
\hline Decreased & $26(6.28)$ & $13(8.67)$ & \\
\hline NA & 54 & 25 & \\
\hline Vaccination within 2 days & & & 0.630 \\
\hline No & 350 (93.33) & 137 (94.48) & \\
\hline Yes & $25(6.67)$ & $8(5.52)$ & \\
\hline NA & 93 & 30 & \\
\hline Daycare center & & & 0.134 \\
\hline No & $245(89.09)$ & $85(94.44)$ & \\
\hline Yes & $30(10.91)$ & $5(5.56)$ & \\
\hline NA & 188 & 85 & \\
\hline Sibling & & & 0.114 \\
\hline No & $236(69.21)$ & 87 (76.99) & \\
\hline Yes & 105 (30.79) & $26(23.01)$ & \\
\hline NA & 127 & 62 & \\
\hline \multicolumn{3}{|c|}{ Family members with upper respiratory symptoms } & 0.016 \\
\hline No & $214(62.94)$ & $88(75.21)$ & \\
\hline Yes & $126(37.06)$ & $29(24.79)$ & \\
\hline NA & 128 & 58 & \\
\hline Rash & & & 0.000 \\
\hline No & $418(92.89)$ & $173(100)$ & \\
\hline Yes & $32(7.11)$ & $0(0)$ & \\
\hline NA & 18 & 2 & \\
\hline Capillary refill time (sec) & & & 0.050 \\
\hline$<2$ & $153(100)$ & 39 (97.5) & \\
\hline$\geq 2$ & $0(0)$ & $1(2.5)$ & \\
\hline NA & 315 & 135 & \\
\hline
\end{tabular}

Values are presented as mean \pm standard deviation or number (\%). NA, not applicable. 
Table 3. Univariate and multivariate regression analyses (except for fever without source) of the derivation dataset

\begin{tabular}{|c|c|c|c|c|c|c|c|}
\hline & & \multicolumn{3}{|c|}{ Univariate analysis } & \multicolumn{3}{|c|}{ Multivariate analysis } \\
\hline & & OR & $95 \% \mathrm{Cl}$ & P-value & OR & $95 \% \mathrm{Cl}$ & P-value \\
\hline \multirow[t]{2}{*}{ Sex } & Female & 1 & & & 1 & & \\
\hline & Male & 2.99 & $2.04-4.37$ & 0.000 & 3.99 & $1.84-8.63$ & 0.000 \\
\hline \multirow[t]{3}{*}{ Past medical history } & None & 1 & & & 1 & & \\
\hline & Other & 1.06 & $0.61-1.84$ & 0.820 & 1.84 & $0.60-5.64$ & 0.317 \\
\hline & Genito-urinary & 2.49 & $1.38-4.49$ & 0.000 & 3.89 & $1.18-12.73$ & 0.025 \\
\hline \multirow[t]{2}{*}{ Age (mo) } & $\geq 12$ & 1 & & & 1 & & \\
\hline & $<12$ & 4.78 & $2.75-8.27$ & 0.000 & 9.75 & $2.99-31.70$ & 0.000 \\
\hline \multirow[t]{4}{*}{ Body temperature } & $<38$ & 1 & & & 1 & & \\
\hline & 38 to $<39$ & 0.68 & $0.46-1.02$ & 0.067 & 1.19 & $0.52-2.68$ & 0.675 \\
\hline & 39 to $<40$ & 0.54 & $0.30-0.98$ & 0.044 & 0.66 & $0.20-2.21$ & 0.510 \\
\hline & $\geq 40$ & 1.68 & $0.49-5.74$ & 0.407 & 3.25 & $0.09-113.31$ & 0.514 \\
\hline \multirow[t]{2}{*}{ Fever without source } & No & 1 & & & - & & \\
\hline & Yes & 3.12 & $1.40-6.97$ & 0.005 & - & & \\
\hline \multirow[t]{5}{*}{ Duration of fever (hr) } & $<24$ & 1 & & & 1 & & \\
\hline & 24 to $<48$ & 1.04 & $0.67-1.00$ & 0.851 & 1.06 & $0.41-2.71$ & 0.892 \\
\hline & 48 to $<72$ & 0.65 & $0.33-1.20$ & 0.223 & 0.83 & $0.22-3.10$ & 0.793 \\
\hline & 72 to $<96$ & 1.50 & $0.74-3.00$ & 0.254 & 0.80 & $0.19-3.25$ & 0.760 \\
\hline & $\geq 96$ & 1.36 & $0.78-2.30$ & 0.268 & 1.55 & $0.48-5.04$ & 0.460 \\
\hline \multirow[t]{4}{*}{ Activity } & Well & 1 & & & 1 & & \\
\hline & Mildly decreased & 1.25 & $0.78-1.99$ & 0.347 & 0.90 & $0.29-2.78$ & 0.860 \\
\hline & Decreased & 1.14 & $0.65-1.98$ & 0.639 & 0.21 & $0.04-1.09$ & 0.063 \\
\hline & Poor & 0.57 & $0.19-1.72$ & 0.325 & 0.22 & $0.02-2.14$ & 0.196 \\
\hline \multirow[t]{4}{*}{ Feeding (\%) } & $>100$ & 1 & & & 1 & & \\
\hline & 80 to $<100$ & 0.74 & $0.42-1.30$ & 0.304 & 0.77 & $0.23-2.58$ & 0.676 \\
\hline & 50 to $<80$ & 0.82 & $0.47-1.42$ & 0.481 & 0.35 & $0.05-2.10$ & 0.253 \\
\hline & $<50$ & 2.14 & $1.28-3.56$ & 0.003 & 3.86 & $0.94-15.84$ & 0.060 \\
\hline \multirow[t]{3}{*}{ Urination } & Well & 1 & & & 1 & & \\
\hline & Mildly decreased & 0.78 & $0.38-1.57$ & 0.489 & 2.64 & $0.61-11.48$ & 0.193 \\
\hline & Decreased & 1.38 & $0.69-2.77$ & 0.359 & 2.59 & $0.42-15.86$ & 0.301 \\
\hline \multirow[t]{2}{*}{ Vaccination within 2 days } & No & 1 & & & 1 & & \\
\hline & Yes & 0.81 & $0.35-1.85$ & 0.630 & 0.74 & $0.12-4.32$ & 0.743 \\
\hline \multirow[t]{2}{*}{ Daycare center } & No & 1 & & & 1 & & \\
\hline & Yes & 0.48 & $0.18-1.27$ & 0.142 & 1.09 & $0.23-5.17$ & 0.904 \\
\hline \multirow[t]{2}{*}{ Sibling } & No & 1 & & & 1 & & \\
\hline & Yes & 0.67 & $0.40-1.10$ & 0.115 & 0.30 & $0.07-1.22$ & 0.095 \\
\hline \multirow{2}{*}{$\begin{array}{l}\text { Family members with upper } \\
\text { respiratory symptoms }\end{array}$} & No & 1 & & & 1 & & \\
\hline & Yes & 1.78 & $1.11-2.86$ & 0.016 & 1.04 & $0.27-3.93$ & 0.945 \\
\hline
\end{tabular}

$\mathrm{OR}$, odds ratio; $\mathrm{Cl}$, confidence interval.

the proportions of UTIs between the two hospitals (27.2\% in the derivation set, $24.4 \%$ in the validation set, $\mathrm{P}=0.243$ ). There were significant differences between the two hospitals, except for the incidence of a past history, FWS, vaccination within 2 days, and rash (Table 1). All male patients were found to be uncircumcised.

The demographics of the derivation group are shown in Table 2 . There was no significant difference in the duration of fever or BT between the two groups. There were more girls (52.35\% vs. $26.86 \%$, $\mathrm{VI}$ vs. UTI, $\mathrm{P}<0.001$ ) and a lower incidence of a past history of UTI (5.77\% vs. $13.14 \%$, VI vs. UTI, $P=0.008$ ) in the $\mathrm{VI}$ group than in the UTI group. There were more children $<12$ months of age in the UTI group ( $67.52 \%$ vs. $90.86 \%$, VI vs. UTI, $\mathrm{P}=0.008$ ), and FWS was more common in the UTI group than in the VI group (15.57\% vs. $36.59 \%$, VI vs. UTI, $P=0.004)$. The activity, urination amount, incidence of vaccination within 2 days, daycare center visit, and the presence of siblings were not significantly different between the groups. There were more family members with upper respiratory symptoms in the VI group than in the UTI group (37.06\% vs. $24.79 \%$, VI vs. UTI, $\mathrm{P}=0.016)$. A total of 32 patients $(7.11 \%)$ experienced rash in the $\mathrm{VI}$ group, and none of the patients experi- 
Table 4. Stepwise logistic regression analysis

\begin{tabular}{|c|c|c|c|c|c|}
\hline Group & & Adjusted OR & Coef & $95 \% \mathrm{Cl}$ & P-value \\
\hline \multirow[t]{2}{*}{ Sex } & Female & 1 & & & \\
\hline & Male & 2.93 & 1.07 & $1.79-4.81$ & $<0.001$ \\
\hline \multirow[t]{2}{*}{ Age (mo) } & $>12$ & 1 & & & \\
\hline & $\leq 12$ & 6.32 & 1.98 & $2.91-13.71$ & $<0.001$ \\
\hline \multirow[t]{3}{*}{ Past medical history } & None & 1 & & & \\
\hline & Other & 1.79 & 0.58 & $0.87-3.69$ & 0.110 \\
\hline & Genito-urinary & 4.20 & 1.43 & $1.81-9.72$ & $<0.001$ \\
\hline \multirow{2}{*}{$\begin{array}{l}\text { Family members with upper respiratory } \\
\text { symptoms }\end{array}$} & No & 1 & & & \\
\hline & Yes & 0.41 & -4.32 & $0.25-0.69$ & $<0.001$ \\
\hline
\end{tabular}

$\mathrm{OR}$, odds ratio; $\mathrm{Cl}$, confidence interval; Coef, coefficients.

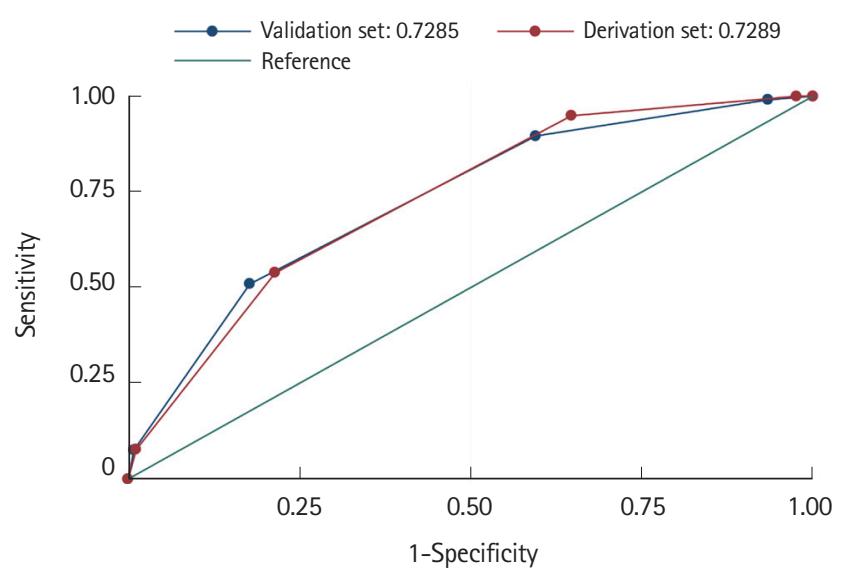

\begin{tabular}{|l|l|c|c|c|c|c|c|}
\hline & & $\geq 0$ & $\geq 1$ & $\geq 2$ & $\geq 3$ & $\geq 4$ & $>4$ \\
\hline Derivation (\%) & Sensitivity & 100 & 100 & 94.87 & 53.85 & 7.69 & 0.00 \\
\cline { 2 - 8 } & Specificity & 0.00 & 2.35 & 35.29 & 78.53 & 98.82 & 100 \\
\hline \multirow{2}{*}{ Validation (\%) } & Sensitivity & 100 & 99.06 & 89.62 & 50.94 & 7.55 & 0.00 \\
\cline { 2 - 8 } & Specificity & 0.00 & 6.56 & 50.94 & 82.24 & 99.18 & 100 \\
\hline
\end{tabular}

Fig. 2. The receiver operating characteristic curve of the clinical prediction models. The area under the receiver operating characteristic curve of the derivation set was 0.7289 , and the area under the receiver operating characteristic curve of the validation set was 0.7285 .

enced rash in the UTI group $(P<0.001)$ (Table 2). A large amount of data was missing in the patients for the variables FWS and CRT, and the number of patients who had a CRT $>2$ seconds was very small. Therefore, we excluded the variables FWS, CRT, and rash in the multivariate logistic regression analysis.

In the multivariate analysis, male sex, a past history of urinary system conditions, and younger age than 12 months old were found to be more associated with UTIs than VIs (Table 3).

Using stepwise regression analysis, we identified sex, age, a past history of genitourinary system conditions, and family members with upper respiratory symptoms as significant variables. The clinical model we created included four dichotomous clinical risk factors (male sex, age $\leq 12$ months, past history of UTI, and fam- ily members with upper respiratory symptoms) (Table 4).

There was no difference in the AUROC when the clinical model derived from the derivation dataset was applied to the validation dataset (Fig. 2) (AUROC 0.7289 in the derivation dataset and 0.7285 in the validation dataset). When we set a decision threshold cutoff value $\geq 1$, the sensitivity was $100 \%$ in the derivation dataset and $99.06 \%$ in the validation dataset. The possibility of missing a UTI was $<1 \%$.

The AUROC for the AAP model was 0.61 (age, BT, duration of fever, and FWS) for girls and 0.52 (BT, duration of fever, and FWS) for boys. We found that the newly derived model was superior to the AAP model (Fig. 3).

In the tree analysis, children $\geq 12$ months of age and those without a past history of UTI had a very low likelihood of UTIs. Infants $<12$ months of age were less likely to have UTIs if they were girls or had a family member with upper respiratory symptoms (Fig. 4).

\section{DISCUSSION}

We developed a new tool to predict UTIs in young pediatric patients using prospectively collected fever registry data. To the best of our knowledge, this is the first study to develop a UTI prediction tool using prospectively collected data. In this study, patients $<24$ months of age who visited the ED with fever were more likely to have UTIs if they were uncircumcised boys, were $<12$ months of age, had a past history of UTI, and did not have a family member with symptoms of respiratory infection.

In the tree analysis, children $\geq 12$ months of age and those without a past history of urinary tract system conditions had a very low likelihood of UTIs and did not require urinalysis. Although infants $<12$ months of age are not likely to have UTIs if they are girls or have upper respiratory symptoms in their family, a urine test is needed to exclude UTI (Fig. 4).

Previous studies have been conducted on factors that can pre- 

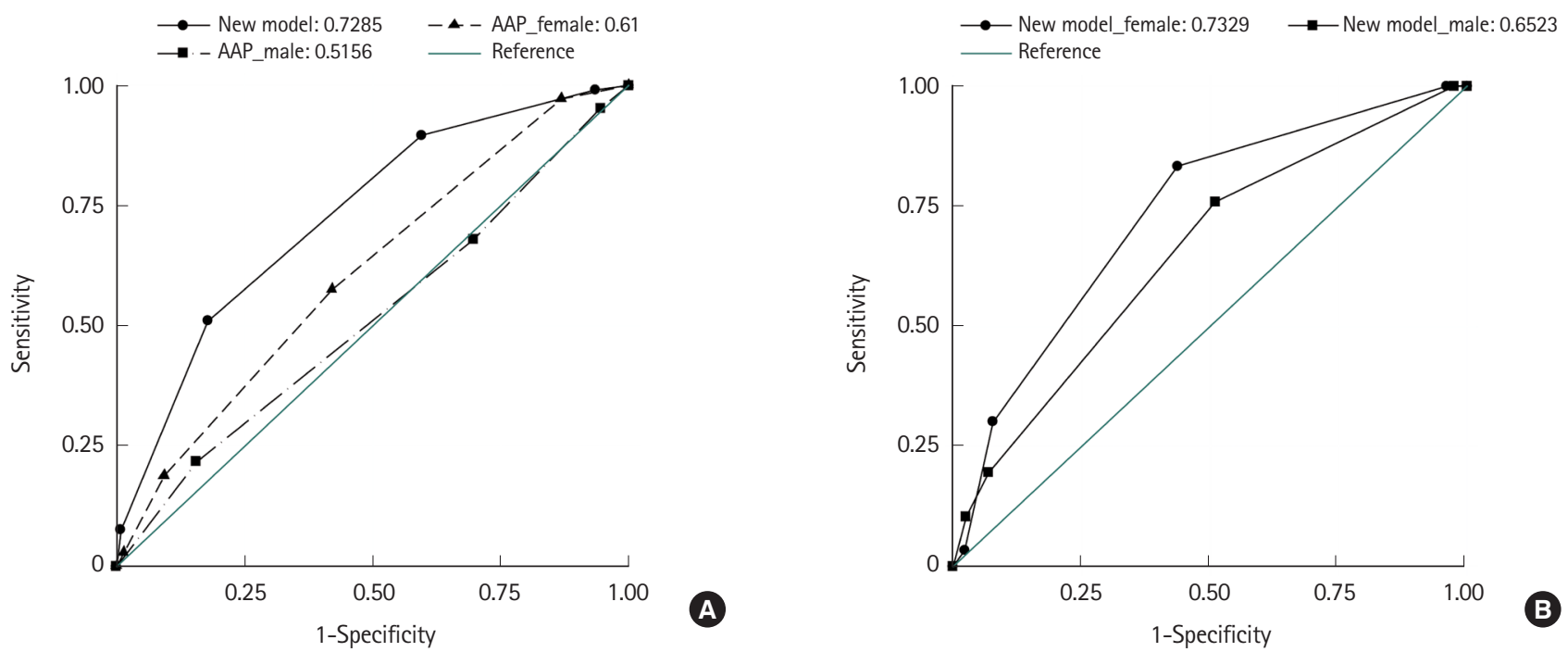

Fig. 3. The comparison of the new model and the American Academic of Pediatrics (AAP) model. The area under the receiver operating characteristic curve for the AAP model was 0.61 for females and 0.52 for males (girls: age, body temperature, duration of fever and fever without source, boys: body temperature, duration of fever, and fever without source) (A). In contrast, in the new model, the area under the receiver operating characteristic curve was 0.73 for females and 0.65 for males (B).

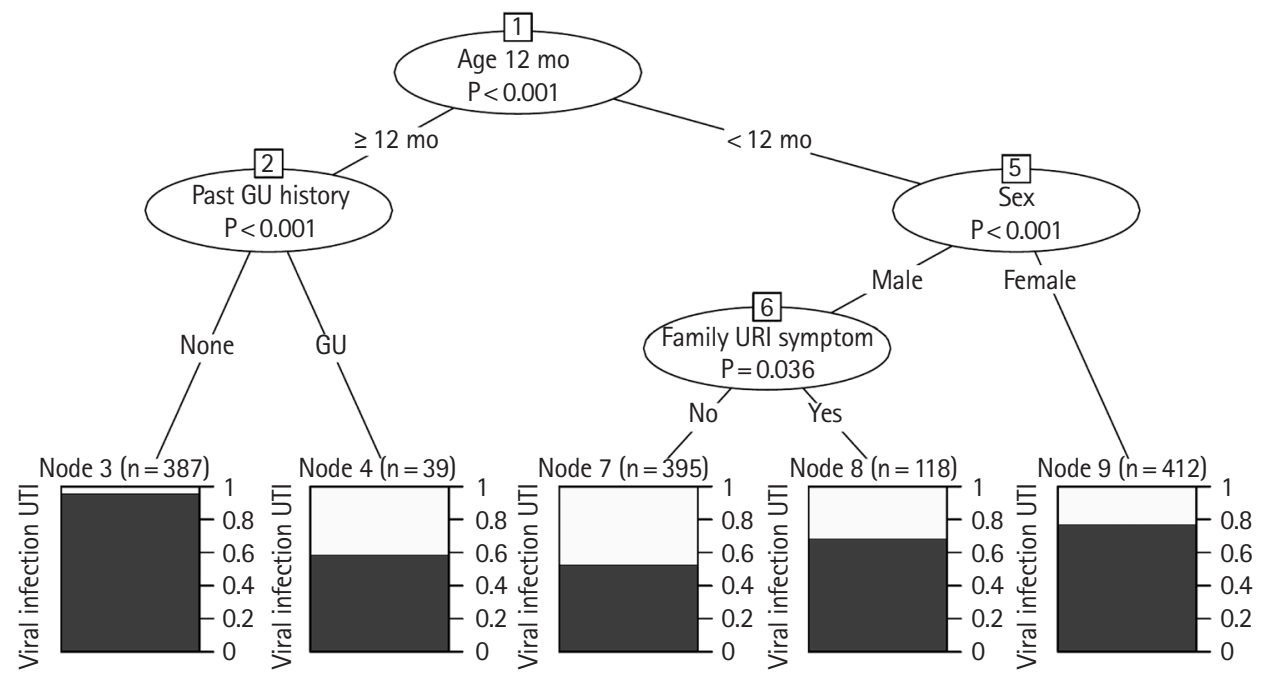

Fig. 4. The tree analysis. In the tree analysis, the children $\geq 12$ months of age and those without a past history of urinary tract infection (UTI) had a very low likelihood of UTI and did not require urinalysis. Although infants $<12$ months of age are less likely to have UTIs if they are female or have upper respiratory symptoms in their family, a urine test is needed to exclude UTIs. GU, genitourinary; URI, upper respiratory infection.

dict UTIs., ${ }^{2,7}$ The predictive factors for UTIs in girls were as follows: age $<12$ months, white race, fever $>39^{\circ} \mathrm{C}$, fever for $>2$ days, and no other sources of fever. ${ }^{7}$ In a study of factors predicting UTIs in boys, the predictive factors included being uncircumcised, fever $>39^{\circ} \mathrm{C}$, fever lasting $>2$ days, and no other source of fever. ${ }^{11}$ Based on these studies, the AAP suggested the following criteria for performing a urinalysis in girls and boys: for female infants $\geq 2$ factors: white race, age $<12$ months, temperature $\geq 39^{\circ} \mathrm{C}$, fever $\geq 48$ hours, and no other source of fever; for male infants if uncircumcised or $\geq 3$ factors: nonblack race, temperature $\geq 39^{\circ} \mathrm{C}$, fever $\geq 24$ hours, and no other source of fever.

The differences between this study and previous studies are that boys and girls were included together in the prediction tool, no ethnic differences were reflected, and not all boys included in the data were circumcised.

The prevalence of UTI in infants with fever varies widely between studies and is reported to be approximately $7 \%$ overall. Before 3 months of age, the prevalence is higher in boys than in girls and is found to be 20\% among boys who have never been circumcised; however, after 3 months of age, the prevalence is 
higher among girls than among boys. ${ }^{12}$ Our study found that boys were more likely to have UTIs than girls, presumably because all of the boys included in the study had not been circumcised.

The AAP guideline recommends urine testing for individuals with a fever $>39^{\circ} \mathrm{C}$, based on previous studies. However, $>87 \%$ of individuals with adenovirus infections have been reported to have a fever $>39^{\circ} \mathrm{C}_{1}^{13}$ and patients with enterovirus infection have been reported to have an average temperature of $39^{\circ} \mathrm{C}$ up to $40.6^{\circ} \mathrm{C}_{i}^{14}$ therefore, fever $>39^{\circ} \mathrm{C}$ is a common symptom of $\mathrm{Vl}$. In fact, in our study, the $\mathrm{VI}$ group included more patients with a fever $>39^{\circ} \mathrm{C}$ than the UTI group, and the UTI group included more patients with a fever $<38^{\circ} \mathrm{C}$ than the $\mathrm{Vl}$ group. Therefore, it appears inappropriate to use fever $>39^{\circ} \mathrm{C}$ as a predictor of UTI. In addition, it is not appropriate to predict UTI because it is common for patients with $\mathrm{VI}$ to show a fever for $>2$ days. ${ }^{15-17}$

Because we collected the data prospectively, we were able to collect data regarding the general condition of the patient and respiratory symptoms among family members from the guardian of the patient. As a result, there was no difference between the two groups in terms of the general condition of the patients as reported by the caregiver. However, the presence of a family member with symptoms of respiratory infections was more likely to suggest VI than UTI.

When the developed UTI prediction tool was applied to other hospital data with different patient characteristics, the AUROC was relatively high; it was higher than that of the prediction tool recommended by the AAP.

In pediatric EDs, many febrile patients have occult bacteremia, some of who appear well, which can be perplexing for clinicians. ${ }^{18}$ There is a tendency to raise concerns regarding complications or long-term sequela of UTIs. It is essential to diagnose UTIs early and not to misdiagnose UTIs. The threshold cutoff of $\geq 1$ had a sensitivity of 100\% in the derivation dataset and $99.06 \%$ in the validation dataset, which was remarkable. In addition to the traditional risk factors outlined in the AAP guidelines (duration of fever, highest BT), we can generate a clinical decision rule that has high sensitivity, which means that the possibility of failure of diagnosis will be $<1 \%$. Clinical prediction tools are not intended to help physicians diagnose UTIs but are intended to help them determine when to conduct tests to identify UTIs.

In this dataset, the prediction model of the AAP performed poorly at predicting UTIs. There are many reasons for this issue; FWS is regarded as one of the crucial predictors of UTIs. ${ }^{18,19}$ However, the statistical significance could not be confirmed because there were many missing data points in our dataset. We agree that FWS is a powerful variable that can predict UTIs. However, it has limitations. The finding of FWS is very subjective, and the accu- racy varies greatly depending on the experience of the physician. It is difficult to evaluate FWS as an objective predictor of UTIs. Circumcision reduces preputial colonization and results in a decrease in UTIs in febrile boys. There is also the possibility of false positives for bacterial urine cultures; however, uncircumcised boys were at an increased risk of UTIs. ${ }^{4,20}$ Because the population comprised a single race and all the boys included in our study were not circumcised, the AAP prediction tool for boys was assigned a score of +1 from the beginning, and the variable, race was excluded from the comparison with the AAP predictor. Therefore, when applying the AAP prediction tool to our data, the diagnostic power may be lower than that in previous studies.

Our study has some limitations. First, there were many missing records of FWS. FWS is an important predictor of UTIs, although it was often found missing in our data; therefore, if FWS was included in the analysis, many cases would need to be excluded and could not be analyzed. Accordingly, we need to perform a prospective study that includes the FWS as a part of the prediction tool. Second, since our sample comprised participants of a single race and all boys were uncircumcised, it appears unreasonable to compare our prediction tool directly with the AAP prediction tool. However, in countries where ethnic differences are not great, such as Korea, this prediction tool can be used more effectively than the AAP prediction tool. In addition, the degree and duration of fever in the AAP prediction tool are considered to be inadequate for distinguishing UTIs from VIs. Third, the process of identifying patients in the VI group was retrospective. There may be selection bias because laboratory tests were not performed on young pediatric patients suspected of having Vls. However, the pediatric emergency specialist continued to review the fever registry and followed the patients, and when classifying the VI group, two physicians reviewed the registry data. Most febrile children came to clinics for follow-ups.

In summary, we developed a clinical tool to predict UTIs, which may help determine whether laboratory tests, such as a urinalysis, are necessary for young pediatric patients with fever in EDs. Patients $<24$ months of age who visited the ED with fever were increasingly likely to have UTIs if they were uncircumcised boys, were $\leq 12$ months of age, had a past history of UTIs, and did not have a family member with symptoms of respiratory infection. Further, a prospective study that includes the variable FWS in the prediction tool needs to be conducted.

\section{CONFLICT OF INTEREST}

No potential conflict of interest relevant to this article was reported. 


\section{REFERENCES}

1. Bandyopadhyay S, Bergholte J, Blackwell CD, Friedlander JR, Hennes $\mathrm{H}$. Risk of serious bacterial infection in children with fever without a source in the post-Haemophilus influenzae era when antibiotics are reserved for culture-proven bacteremia. Arch Pediatr Adolesc Med 2002;156:512-7.

2. Shaikh N, Hoberman A, Hum SW, et al. Development and validation of a calculator for estimating the probability of urinary tract infection in young febrile children. JAMA Pediatr 2018; 172:550-6.

3. Coulthard MG, Lambert HJ, Vernon SJ, Hunter EW, Keir MJ, Matthews JN. Does prompt treatment of urinary tract infection in preschool children prevent renal scarring: mixed retrospective and prospective audits. Arch Dis Child 2014;99:342-7.

4. Subcommittee on Urinary Tract Infection. Reaffirmation of AAP Clinical Practice Guideline: the diagnosis and management of the initial urinary tract infection in febrile infants and young children 2-24 months of age. Pediatrics 2016;138: e20163026.

5. Okarska-Napierała M, Wasilewska A, Kuchar E. Urinary tract infection in children: diagnosis, treatment, imaging: comparison of current guidelines. J Pediatr Urol 2017;13:567-73.

6. Chiang EL, Shaikh N. Re: two-step process for ED UTI screening. Pediatrics 2017;139:e20163794A.

7. Gorelick MH, Shaw KN. Clinical decision rule to identify febrile young girls at risk for urinary tract infection. Arch Pediatr Adolesc Med 2000;154:386-90.

8. Korbel L, Howell M, Spencer JD. The clinical diagnosis and management of urinary tract infections in children and adolescents. Paediatr Int Child Health 2017;37:273-9.

9. Gorelick MH, Hoberman A, Kearney D, Wald E, Shaw KN. Validation of a decision rule identifying febrile young girls at high risk for urinary tract infection. Pediatr Emerg Care 2003;19: 162-4.

10. Hothorn T, Hornik K, Strobl K, Zeileis A. party: a laboratory for recursive partitioning [Internet]. pkg:party [cited 2020 0ct 10]. Available from: http://party.R-forge.R-project.org.

11. Shaikh N, Morone NE, Lopez J, et al. Does this child have a urinary tract infection? JAMA 2007;298:2895-904.

12. Shaikh N, Morone NE, Bost JE, Farrell MH. Prevalence of urinary tract infection in childhood: a meta-analysis. Pediatr Infect Dis J 2008;27:302-8.

13. Lin MR, Yang SL, Gong YN, et al. Clinical and molecular features of adenovirus type 2, 3, and 7 infections in children in an outbreak in Taiwan, 2011. Clin Microbiol Infect 2017;23: 110-6.

14. Huang YC, Chu YH, Yen TY, et al. Clinical features and phylogenetic analysis of Coxsackievirus A9 in Northern Taiwan in 2011. BMC Infect Dis 2013;13:33.

15. Chang LY, Lin TY, Hsu KH, et al. Clinical features and risk factors of pulmonary oedema after enterovirus-71-related hand, foot, and mouth disease. Lancet 1999;354:1682-6.

16. Kaluarachchi D, Kaldas V, Erickson E, Nunez R, Mendez M. When to perform urine cultures in respiratory syncytial virus-positive febrile older infants? Pediatr Emerg Care 2014;30:598601.

17. Oray-Schrom P, Phoenix C, St Martin D, Amoateng-Adjepong Y. Sepsis workup in febrile infants 0-90 days of age with respiratory syncytial virus infection. Pediatr Emerg Care 2003; 19:314-9.

18. Hoberman A, Chao HP, Keller DM, Hickey R, Davis HW, Ellis D. Prevalence of urinary tract infection in febrile infants. J Pediatr 1993;123:17-23.

19. Neri PM, Redden L, Poole $S$, et al. Emergency medicine resident physicians' perceptions of electronic documentation and workflow: a mixed methods study. Appl Clin Inform 2015;6: 27-41.

20. Singh-Grewal D, Macdessi J, Craig J. Circumcision for the prevention of urinary tract infection in boys: a systematic review of randomised trials and observational studies. Arch Dis Child 2005;90:853-8. 
Appendix 1. Fever registry

\begin{tabular}{|c|c|}
\hline Sex & Male, female \\
\hline Age & Months \\
\hline Disposition & Discharge, ward admission, intensive care unit admission, transfer \\
\hline \multirow[t]{13}{*}{ Past medical history } & None \\
\hline & Cardiovascular disease \\
\hline & Respiratory disease \\
\hline & Neurological disease \\
\hline & Gastrointestinal disease \\
\hline & Genitourinary disease \\
\hline & Musculoskeletal disease \\
\hline & Psychiatric disease \\
\hline & Endocrine disease \\
\hline & Ear, nose, throat \\
\hline & Genetic disease \\
\hline & Dermatological disease \\
\hline & Miscellaneous \\
\hline Body temperature $\left({ }^{\circ} \mathrm{C}\right)$ & $<38,38$ to $<39,39$ to $<40, \geq 40$ \\
\hline Duration of fever (hr) & $<24,24$ to $<48,48$ to $<72,72$ to $<96$, $\geq 96$ \\
\hline Activity & Good, mildly decreased, decreased, poor \\
\hline Feeding $(\%)$ & 100,80 to $<100,50$ to $<80,<50$ \\
\hline Urination & Good, mildly decreased, decreased \\
\hline Vaccination within 2 days & Yes/no \\
\hline Daycare center & Yes/no \\
\hline Siblings & Yes/no \\
\hline Family member with upper respiratory infection symptoms & Yes/no \\
\hline Rash & Yes/no \\
\hline Fever without source & Yes/no \\
\hline
\end{tabular}

This original fever registry collects clinical information of febrile children who visit the emergency department of both hospitals. 